\title{
INCORPORATION EFFECT OF MANGO (Mangifera indica) KERNEL FLOUR ON THE PHYSICOCHEMICAL, ANTIOXIDANT AND SENSORIAL PROPERTIES OF PASTA
}

\author{
YONG PUI YEE AND NIZAHA JUHAIDA MOHAMAD*
}

Faculty of Fisheries and Food Science, Universiti Malaysia Terengganu, 21030 Kuala Nerus, Terengganu, Malaysia.

*Corresponding author: niezaju@umt.edu.my

http://doi.org/10.46754/umtjur.2021.10.021

\begin{abstract}
The incorporation of mango kernel flour (MKF) into pasta was carried out to maximise the utilisation of waste from mango industries. Mango kernels are reported to make up between $45 \%$ and $75 \%$ of a mango seed and its high antioxidant properties make it an ideal ingredient in pastas. This study aims to determine the physiochemical, antioxidant properties, and sensory acceptability of fresh pasta made with MKF. There were four formulations of pasta where MKF was incorporated at $0 \%, 2.5 \%, 5.0 \%$ and $7.5 \%(\mathrm{w} / \mathrm{w})$. The pasta was analysed for its proximate composition, cooking quality, antioxidant properties, physical analysis, and sensory acceptance. The incorporation of MKF did not generally affect the proximate composition of pasta, however the fat content was increased at $7.5 \%$ MKF. The high MKF content had also affected the cooking properties, colour and texture of the pasta. As expected, the substitution of MKF increased the antioxidant properties of pasta at the $2.5 \%$ concentration level without affecting the cooking properties, colour and texture of the pasta. The MKF substitution only started to affect the acceptability in terms of colour and texture at $5 \%$ substitution level while other attributes including the overall acceptability was not significantly affected $(\mathrm{p}>0.05)$. In conclusion, since the antioxidant properties of pasta was increased at the lowest level of MKF infusion while other properties were not significantly affected, pasta with $2.5 \%$ MKF could potentially increase the dietary value of pasta in terms of antioxidants while promoting the agricultural waste reduction.
\end{abstract}

Keywords: Mango kernel flour, Mangifera indica, fresh pasta, antioxidant properties.

\section{Introduction}

Mangoes otherwise known as Mangifera indica $L$. belong to the Anacardiaceae family. The high nutritional value of mango paired with its great taste and aroma are among the reasons why mangoes are popular the world over (Ibarra et al., 2015). Mangoes have a high-water content and are high in fibre, minerals, vitamins and antioxidants (Tharanathan et al., 2006).

Furthermore, since mangoes are the second most traded tropical fruit and the fifth in total production in the world, it is also called as the king of fruits (FAOSTAD, 2015). Mangoes are a seasonal fruit and are perishable in nature, therefore, in order to preserve mangoes, it is processed in a variety of different ways including being frozen, juiced, jellied, pickled, turned into leather, nectar, puree or sliced. It is also popular as an ice cream (Ramteke \& Eipeson, 1997; Loelillet, 1994).
However, only about $20 \%$ of the mango fruit are used for food production while the other parts are discarded as waste (Loelillet, 1994). These include the seeds and peels.

Mango seeds are of the largest component in the mango waste despite having high concentrations of nutrients and antioxidants (Puravankara et al., 2000). According to Central Food Technological Research Institute (CFTRI) (1985), the utilisation of mango pulp hovers between $45 \%$ and $65 \%$ depending on the type of processed product. As a result, there is about one million tons of mango seeds are being annually produced as wastes (Abdalla et al., 2006).

The percentage of mango seed to pulp was reported to be between $20 \%$ and $60 \%$ of the whole fruit weight, (Beerh et al.,1976; Hemavathy et al., 1988), depending on the variety of the fruit. The kernel (inside the 
seed) on the other hand, made up between $45 \%$ and $75 \%$ of the whole seed, and $20 \%$ of the whole fruit, depending on the type of mango (Maisuthisakul \& Gordon, 2009).

Mango seed kernels are reported to have a $6 \%$ protein, $11 \%$ fat, $77 \%$ carbohydrate, $2 \%$ crude fiber and $2 \%$ ash content on dry basis calculation (Zein et al., 2005). The protein of mango seed kernels are reportedly of good quality despite its small quantity (Seleim et al., 1999). Among all the mango parts, mango seed kernels are reported to have highest amount of polyphenols with the most potent antioxidative capabilities compared to both mango pulp and peels (Masibo \& He, 2008). A previous study by Soong and Barlow (2004) also supported this finding. Mango kernels have a higher mineral content of calcium, magnesium and potassium (Ifesan, 2017).

A study by Yatnatti et al. (2014) showed that mango seed kernels can be processed into flour which can be incorporated into food products as a supplement. Most of the studies on mango kernel flour (MKF) have been focused on the application of MKF in bakery products such as bread and biscuit, and these products have had positive results proving that MKF has the potential to be an alternative to flour for baked goods (Kaur \& Brar, 2017; Menon et al., 2014).

However, no study has been carried out on the effects of incorporating mango kernel flour to pasta. Pasta has become one of the most popular foods among children and young adults in Malaysia, due to its ease-of-use in meal preparation. Therefore, this study aims to ascertain if MKF may be used as an alternative flour for the production of pasta and to see if the results are comparable to the results obtained by MKF in the production of baked products.

Pasta is a stable and simple food product that has been identified as a healthy food by various countries due to its low-fat content, lack of cholesterol and low glycemic index (GI) rating (Cleary \& Brennan, 2006). According to Thomas et al. (1991), low glycemic index foods such as legumes and pasta can release glucose to the blood slowly but continuously without a sharp increase of insulin which is good for health. The incorporation of ingredients other than the semolina flour into pasta has been done in many previous studies. The studies have also been done on the incorporation of wakame seaweed into pasta in order to increase its antioxidant levels (Prabhasankar et al., $2009 \mathrm{~b}$ ), the production of fiber-enriched pasta by incorporating cereal bran (Kaur et al., 2012) and the production of pasta with millet flours and carrot pomace (Gull et al., 2015).

The potential of MKF as a pasta ingredient is hoped to boost the production of MKF and reduce the amounts of mango waste. Besides, pasta incorporated with MKF has additional nutritional value given its antioxidant properties and high phenolic content (Ashoush \& Gadallah, 2011). Thus, MKF pasta may boost the levels of antioxidants taken by people in Malaysia, especially those who do not like to eat fruits and vegetables.

In addition, the food manufacturers can produce a low cost but high-quality pasta by substituting some of the semolina flour with MKF. The objectives of this study were to determine the physicochemical and antioxidant properties of pasta incorporated with MKF, and also to determine its acceptability as pasta variant by consumers and end-users.

\section{Materials and Methods}

\section{Materials}

Semolina flour for pasta making imported from United States was purchased from Radiant Code Sdn Bhd. Mangoes were purchased from the local market in Terengganu, and egg white powder was purchased from Eugene Chemical Sdn. Bhd, Penang, Malaysia.

\section{Preparation of MKF}

The mangoes were washed thoroughly under running tap water. The peel and flesh of mangoes were separated from the seed manually with a knife. Then, the kernel was removed from the 
seeds and rinsed in running water in order to remove any contaminants.

The mango kernels were then blanched in $83^{\circ} \mathrm{C}$ hot water for two minutes in order to stop any enzymatic reactions. Then, mango kernels were chopped and dried in a cabinet dryer at $50^{\circ} \mathrm{C}$ for 150 minutes until its moisture content ranged between $8.0(\mathrm{~g} / 100 \mathrm{~g})$ and $10.0(\mathrm{~g} / 100$ $\mathrm{g})$. The dried mango kernels were then ground into a powder with a basic grinder (SIGMAALDRICH, USA) and then passed through a $250 \mu \mathrm{m}$ standard sieve (Menon et al., 2015).

The flour was then stored in an airtight sealed bag and kept away from sunlight until needed for further analysis (Menon et al., 2014).

\section{Preparation of Pasta}

Some $200 \mathrm{~g}$ of pasta was prepared using a combination of MKF and semolina flour in different ratios as shown in Table 1. An additive of $1 \%$ of egg white powder was added to enhance its gluten network. The process of making the fresh pasta is a modification on the method suggested by Prabhasankar et al. (2009a) and Croce (1997).

200 grammes of semolina flour was mixed with water $\left(40^{\circ} \mathrm{C}\right.$ to $\left.45^{\circ} \mathrm{C}\right)$ until it reached a doughy consistency with a moisture level of between $34 \%$ and $38 \%$. All the ingredients were mixed in a KitchenAid, USA dough mixer for around 10 minutes at a consistent speed. The dough was then rested for about 30 minutes. The dough was sheeted several times and folded in half with a pasta machine after it was sufficiently rested. The thickness of sheeted dough was passed through a pasta machine to give it a thickness of $1.0 \mathrm{~mm}$. Then, the flattened dough was shaped into $25 \mathrm{~cm}$ long fettuccine in the pasta machine. The pasta samples were stored in the chiller for between two and three days before further analysis. The pasta was then cooked at its optimum cooking time before analysis.

Table 1: Pasta formulations

\begin{tabular}{ccc}
\hline Formulation & Amount of MKF (g) & Amount of Semolina Flour (g) \\
\hline A & 0 & 100 \\
B & 2.5 & 97.5 \\
C & 5.0 & 95 \\
D & 7.5 & 92.5 \\
\hline
\end{tabular}

\section{Proximate Analysis of Cooked Pasta}

The determination of the nutritional composition of cooked pasta was conducted in accordance with the standard method of proximate determination set by the Association of Official Analytical Chemists (AOAC) (AOAC, 1990). The proximate composition of the pasta includes moisture, ash, crude protein, crude fat, crude fibre and carbohydrates.

The crude protein, fat and crude fibre determinations were made by using Kjeldahl instrument (VAP 30s, Gerhardt, Germany), Soxtec instrument from Soxtec $\AA$ Avanti 2055 System (FOSS, China) and FiberGerhardt FiberBag System, FB6 (Germany), respectively. Then, the total carbohydrates was determined by subtracting the total proximate results from $100 \%$. All of the data collected was reported in the form of mean standard deviation.

\section{Determination of Pasta Cooking Time}

Following the AACC method 66-50 (AACC, 2005), the pasta cooking time was determined by taking $10 \mathrm{~g}$ of dried pasta and putting it into a beaker containing $150 \mathrm{ml}$ of boiling water. The pasta was stirred until it reached a vigorous rolling boil to prevent it from sticking together. A pasta strand was removed from the cook at 30 second intervals and squeezed between two glass slides. The optimum cooking time was achieved when the white centre of ungelatinised starch had just disappeared. 


\section{Determination of Cooking Loss}

The cooking loss determination was measured by draining the cooked pasta in order to collect the cooking water. The cooking water then was evaporated in an oven (Binder VD, Germany) at $105^{\circ} \mathrm{C}$ overnight in accordance with AACC method 16-50 (AACC, 1995). The weight of dried residue left after the drying process was then taken as the percentage of cooking loss by applying the following formula:

$$
\begin{aligned}
& \text { Cooking loss }(\%) \\
& =\frac{\text { Weight of dried cooking water residue }}{\text { Weight of original pasta }} \times 100 \%
\end{aligned}
$$

\section{Determination of Swelling Index}

The swelling index (SI) of cooked pasta was determined based on the method described by Cleary and Brennan (2006) on their published work. The weight of cooked pasta was taken immediately after it was removed from the boiling water. Then, the cooked pasta was dried in oven at $105^{\circ} \mathrm{C}$ overnight. The swelling index was calculated using the formula below:

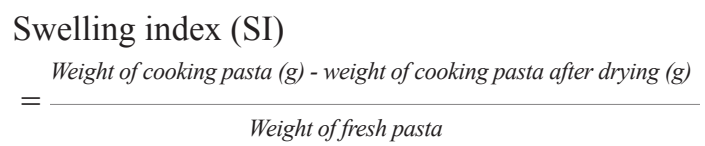

\section{Determination of Water Absorption Index}

The determination of the water absorption index was conducted using a similar method to the one used to make the swelling index determination except that the cooked pasta did not undergo the drying process. The percentage of water absorption was calculated as follows:

Water absorption index $=$

Weight of cooking pasta $(g)$ - weight of fresh pasta $(g)$

Weight of fresh pasta ( $g$ )

\section{Determination of Colour}

The colour of cooked pasta was determined by using Minolta Chromameter CR-310 (Konica, Japan). The calibration was done on the white tile (calibrate plate) before analysis. According to Petitiot (2010), the Hunter L*, a* , b* values were measured. The results were taken as the mean of three measurements on cooked pasta samples which were cut into rectangles with the following $8.0 \mathrm{~cm} 4.0 \mathrm{~cm}$ dimensions. Five readings were taken and the data were reported as means \pm standard deviation.

\section{Determination of Firmness}

According to AACC (2003) method 16-50, the firmness of cooked pasta was evaluated by using $30 \mathrm{~kg}$ of load cell attached with a $1 \mathrm{~mm}$ flat Perspex knife blade. The fixed parameters settings had been modified according to Foo et al. (2011) as follows: Mode: Measure force in compression; Option: Return to start; PreTest Speed: $1.0 \mathrm{~mm} / \mathrm{s}$; Test speed: $0.1 \mathrm{~mm} / \mathrm{s}$; Post-Test Speed: $10 \mathrm{~mm} / \mathrm{s}$; Distance: $4.98 \mathrm{~mm}$; Data Acquisition Rate: 400 pps. The cooked pasta samples were cut into $70 \mathrm{~mm}$ lengths and four pasta strands were placed straight and flat adjacent to one another on the centre of a heavyduty platform.

The samples were positioned at $90^{\circ}$ angles to the blade and the firmness values were taken from the peaks of a force-time graph.

\section{Determination of Tensile Strength}

Gan et al. (2009) stated the method and formula of determining tensile strength of pasta were also measured by using a Texture analyser, TAXT2 model (Stable Microsystems, England) attached with a $30 \mathrm{~kg}$ load cell.

The distance of the A/SPR probe to move apart was set at $15 \mathrm{~mm}$ and the fixed parameters used were Mode: Measure force in tension; Option: Return to start; Pre-test speed: 3.0 $\mathrm{mm} / \mathrm{s}$; Test speed: $3.0 \mathrm{~mm} / \mathrm{s}$; Post-test speed: 5.0 $\mathrm{mm} / \mathrm{s}$; Distance: $100 \mathrm{~mm}$.

The cooked pasta strands were cut into 250 $\mathrm{mm}$ long sections. The width and thickness of the strands were determined at three different locations to get the average of cross-sectional area of pasta strand using a manual micrometer (Mitutoyo, USA). The tensile strength was calculated using the formula outlined below: 


$$
\alpha=\frac{\mathrm{F}}{\mathrm{A}}
$$

where $\alpha$ is the tensile strength $(\mathrm{Pa}), \mathrm{F}$ is the peak force $(\mathrm{N})$ and $\mathrm{A}$ is the cross-sectional area of the pasta strand $\left(\mathrm{m}^{2}\right)$.

\section{Scanning Electron Microscopy (SEM)}

The cooked pasta samples were first dried in a vacuum dryer (Binder VD, Germany) at $35^{\circ} \mathrm{C}$ for 30 hours. The samples were then cut into small pieces for examining the surface area and cross-sectional area of pasta. Then, the small pieces of dried cooked pasta were attached on the specimen holder which shape like a button cell battery using double-sided scotch tape and were exposed to gold sputtering ( $2 \mathrm{~min}, 2 \mathrm{mbar}$ ).

All samples were subjected to scanning electron microscopic examination using JEOL Scanning Electron Microscope (JSM6360LA, Japan). Micrographs of 250 and 3000 magnifications were selected for result presentation of surface area and cross-sectional area pasta (Sudha \& Leelavathi, 2012).

\section{Extraction of Antioxidant Compounds}

The extraction of antioxidant compounds from cooked pasta were done as described by Beta et al. (2005) with slight modifications. The 20 $\mathrm{ml}$ of acidified methanol ( $\mathrm{HCl}$ : methanol: water, 1:80:20) and $2 \mathrm{~g}$ of sample were mixed in a 150 $\mathrm{ml}$ conical flask and shaken for two hours at 200 rpm using Orbital shaker (IKA, UK).

The mixing was carried out at room temperature with the conical flask was wrapped with aluminum foil to protect sample from light. After that, the mixture was centrifuged at $4000 \mathrm{rpm}$ at $5^{\circ} \mathrm{C}$ for 20 minutes by using multi-purpose centrifuge (GYROZEN Co, Ltd, Korea). The supernatant was then collected and used for the total phenolic compound (TPC assays, DPPH radical scavenging activity, FRAP assays. Extractions were done in duplicate.

\section{Determination of Total Phenolic Content}

Total phenolic content was determined following the Folin-Ciocalteau method (Singleton \& Rossi, 1965) adapted by Beta et al. (2005). The $0.2 \mathrm{ml}$ of supernatant extract was added to 1.5 $\mathrm{mL}$ of Folin-Ciocalteau's reagent $\left(1: 5 \mathrm{H}_{2} \mathrm{O}\right)$.

The mixture was allowed to equilibrate for five minutes after vortex, then $1.5 \mathrm{~mL}$ of sodium carbonate solution $(60 \mathrm{~g} / \mathrm{L})$ was added and vortex for another one minutes. The mixture then was left to react at room temperature for 30 minutes.

Absorbance was read at $725 \mathrm{~nm}$ with spectrophotometer (4001/4, Thermo Spectronic, US) while distilled water was used as blank.

A standard curve of concentration versus absorbance was constructed using gallic acid standard. All tests were done in duplicate for each batch and results expressed as mg equivalent of gallic acid/100 g cooked pasta (mg GAE/100 g).

\section{Determination of 2,2-di(4-tert-octylphenyl)- 1-picrylhydrazyl) (DPPH) Free Radical Scavenging Activity}

The DPPH inhibition assay to measure the antioxidant activity of pasta was followed the method described by Beta et al. (2005) with slightly modification. The $0.1 \mathrm{ml}$ of supernatant extract from the sample that had been centrifuged was added with $3.9 \mathrm{~mL}$ of $0.1 \mathrm{mM}$ DPPH working solution which is a deep violet colour.

The mixture was allowed to stand at room temperature for 30 minutes. The absorbance was read at $515 \mathrm{~nm}$ with spectrophotometer. The control without sample was replaced with 0.1 $\mathrm{ml}$ of methanol. The discoloration of the DPPH radicals indicated the antioxidants contents of cooked pasta. The percentage of scavenging activity was calculated as following equation:

Scavenging activity $(\%)=\frac{\mathrm{Abs}_{\text {control }}-\mathrm{Abs}_{\text {sample }}}{\mathrm{Abs}_{\text {control }}} \times 100$ 
Determination of Ferric Ion Reducing Antioxidant Properties (FRAP)

FRAP analysis was carried out following the method described by Benzie and Strain (1996). FRAP reagent was prepared by mixing $25 \mathrm{ml}$ of $300 \mathrm{mmol} / \mathrm{L}$ sodium acetate buffer, $2.5 \mathrm{ml}$ of $10 \mathrm{mmol} / \mathrm{L}$ 2,4,6-tripyridyl-s-triazine (TPTZ) stock solution and $2.5 \mathrm{ml}$ of $20 \mathrm{mmol} / \mathrm{L}$ ferric chloride $\left(\mathrm{FeCl}_{3}\right)$ solution in the ratio of 10:1:1 $(\mathrm{v} / \mathrm{v} / \mathrm{v})$.

The sodium acetate buffer was prepared by mixing sodium acetate trihydrate and acetic acid in distilled water until the $\mathrm{pH}$ reached 3.6. The TPTZ stock solution was prepared by dissolving TPTZ in $40 \mathrm{mM}$ hydrochloric acid solution. Then, the $20 \mathrm{mM} \mathrm{FeCl}_{3}$ was obtained by dissolving the $\mathrm{FeCl}_{3}$ powder in distilled water. After that, the $0.2 \mathrm{ml}$ of extract was added with $1.8 \mathrm{ml}$ of FRAP solution and then incubated for 30 minutes at $37^{\circ} \mathrm{C}$ in the water bath in a dark environment.

The absorbance of mixture was measured at $593 \mathrm{~nm}$ using a spectrophotometer. Ferric (II) sulphate solutions $(0-100 \mathrm{M})$ was prepared and used to obtain the standard curve. The sample was turned to dark purple colour to indicate that there was an antioxidant reaction.

The results were compared with standard curve and expressed as microgram ferric (II) sulphate equivalent per gram $(\mathrm{g} / \mathrm{g})$.

\section{Sensory Evaluation}

The sensory evaluation of cooked pasta was conducted by using affective test which was performed by 30 untrained panelists that consisted of the students and staff of Universiti Malaysia Terengganu (UMT) from different races ranging between 19 and 50 years of age.

There were four formulations of cooked pasta presented for each panelist at the same time. The cooked pasta was presented in a small sealed plastic container to avoid the loss of quality of pasta. The seven hedonic scales with ' 1 ' representing 'dislike extremely' and ' 7 ' representing 'like extremely' was used for evaluation by panelists.
The sensory attributes of cooked pasta was evaluated in terms of colour, odour, texture, flavour and overall acceptability.

\section{Statistical Analysis}

All treatments of cooked pasta were carried out in duplicate for each batch. The data of each analysis were collected, calculated and recorded as mean and standard deviation. All data were determined by using one-way analysis of variance (ANOVA) and Duncan comparison test with the degree of significant $(p<0.05)$ among the samples. The data analysis was conducted by using Statistical Package for the Social Sciences (SPSS) for data from sensory evaluation.

\section{Results and Discussion}

\section{Nutritional Content of Fresh Mango Kernel Pasta}

The effect of MKF on the nutritional composition of pasta is shown in Table 2. The moisture content of pasta incorporated with MKF range between $55.23 \%$ and $59.31 \%$. Generally, the incorporation of MKF did not influence the moisture content as all formulations with MKF did not differ significantly $(p>0.05)$ with the control. However, the moisture content of Formulation D was significantly higher than Formulations B and C $(\mathrm{p}<0.05)$. The MKF was reported to have a number of carbohydrates (Okpala \& Gibson-Umeh, 2013) that can absorb an amount of water and consequently increased the amount of water in the samples.

The non-gluten flour but high carbohydrate content like MKF has water absorption properties which can compete the starch in water and lengthen the time to develop the dough (Aravind et al., 2012). This statement was also supported by Omobuwajo (2003) who stated that the increasing of water absorption upon the dough development with the ascending level incorporating of tropical tuber flours. The ash, crude protein, and crude fibre contents of the samples did not have any significant different $(p>0.05)$ between each other. The mean value 
range of the ash value, crude protein, and crude fibre in samples were $0.22 \%$ to $0.27 \%, 5.20 \%$ to $5.61 \%$, and $0.65 \%$ to $0.81 \%$ respectively.

MKF was reported to have low protein content (Zein et al., 2005) and low fiber (Zein et al., 2005; Kaur \& Brar, 2007), thus not significantly affecting the pasta composition. The average range of crude fat content for fresh mango kernel pasta was at $0.18 \%$ to $0.81 \%$. The crude fat content of formulation D pasta was significantly $(\mathrm{p}<0.05)$ higher than the other three formulations with ascending result of crude fat content where the percentage of MKF incorporated into the pasta increased. This is because MKF consisted of fairly high amounts of crude fat content of about $10.50 \%$ (Kaur \& Brar, 2007).

Table 2: The proximate analysis of pasta incorporated with MKF

\begin{tabular}{ccccc}
\hline Nutrient Content & $\mathbf{A}(\mathbf{0 \%} \mathbf{M K F})$ & $\mathbf{B} \mathbf{( 2 . 5 \%} \mathbf{M K F})$ & $\mathbf{C}(\mathbf{5 . 0 \%} \mathbf{M K F})$ & $\mathbf{D} \mathbf{( 7 . 5 \%} \mathbf{M K F})$ \\
\hline Moisture & $57.50 \pm 1.11^{\mathrm{ab}}$ & $55.23 \pm 2.54^{\mathrm{b}}$ & $55.59 \pm 2.61^{\mathrm{b}}$ & $59.31 \pm 0.64^{\mathrm{a}}$ \\
Ash & $0.52 \pm 0.08^{\mathrm{a}}$ & $0.61 \pm 0.08^{\mathrm{a}}$ & $0.61 \pm 0.15^{\mathrm{a}}$ & $0.58 \pm 0.01^{\mathrm{a}}$ \\
Fat & $0.18 \pm 0.08^{\mathrm{b}}$ & $0.27 \pm 0.06^{\mathrm{b}}$ & $0.35 \pm 0.07^{\mathrm{b}}$ & $0.81 \pm 0.27^{\mathrm{a}}$ \\
Protein & $5.61 \pm 0.13^{\mathrm{a}}$ & $5.43 \pm 0.39^{\mathrm{a}}$ & $5.30 \pm 0.44^{\mathrm{a}}$ & $5.28 \pm 0.32^{\mathrm{a}}$ \\
Fiber & $0.65 \pm 0.19^{\mathrm{a}}$ & $0.81 \pm 0.10^{\mathrm{a}}$ & $0.79 \pm 0.07^{\mathrm{a}}$ & $0.74 \pm 0.12^{\mathrm{a}}$ \\
Carbohydrate & $35.66 \pm 1.23^{\mathrm{ab}}$ & $38.53 \pm 2.47^{\mathrm{a}}$ & $37.14 \pm 1.97^{\mathrm{a}}$ & $33.71 \pm 0.63^{\mathrm{b}}$ \\
\hline
\end{tabular}

Values are presented as mean \pm standard deviation (mean $\pm 1, \mathrm{n}=4$ ).

Values with different superscript letter in the same column are significant different at $\mathrm{p}<0.05$.

\section{Cooking Properties of Fresh Mango Kernel Pasta}

Table 3 shows the cooking properties of pasta incorporated with MKF. The optimum cooking time of pasta decreased as the percentage of incorporation MKF increased. Incorporation $2.5 \%$ MKF did not differ in cooking time with the control, while increasing to $5 \%$ has shortened the cooking time from four minutes to 3.5 minutes.
The highest addition of MKF decreased the cooking time but there was no significant difference $(p>0.05)$ with pasta containing $5 \%$ MKF. This may be due to the disruption of gluten matrix by MKF, thus weakening the network and reduce the cooking time. This can be explained by the finding from Kaur et al. (2012) stated that the increasing bran and germ particles interrupts the gluten matrix which provided a path of water absorption into the spaghetti, and thus reduced the optimum cooking time.

Table 3: The cooking properties of pasta incorporated with MKF

\begin{tabular}{lllll}
\hline \multirow{2}{*}{ Samples } & \multicolumn{4}{c}{ Cooking Properties } \\
\cline { 2 - 5 } & $\begin{array}{c}\text { Optimum Cooking } \\
\text { Time (min) }\end{array}$ & $\begin{array}{c}\text { Water Absorption (g/ } \\
\mathbf{1 0 0} \mathbf{g} \text { of Raw Pasta }\end{array}$ & $\begin{array}{c}\text { Swelling Index (g of } \\
\text { water/g of dry pasta) }\end{array}$ & $\begin{array}{c}\text { Cooking Loss (g/ } \\
\mathbf{1 0 0} \text { of raw pasta) }\end{array}$ \\
\hline $\mathrm{A}(0 \% \mathrm{MKF})$ & $4.08 \pm 0.15^{\mathrm{a}}$ & $50.36 \pm 5.84^{\mathrm{a}}$ & $1.34 \pm 0.13^{\mathrm{b}}$ & $2.30 \pm 0.10^{\mathrm{c}}$ \\
$\mathrm{B}(2.5 \% \mathrm{MKF})$ & $4.09 \pm 0.14^{\mathrm{a}}$ & $43.32 \pm 3.96^{\mathrm{b}}$ & $1.23 \pm 0.09^{\mathrm{b}}$ & $2.35 \pm 0.15^{\mathrm{c}}$ \\
$\mathrm{C}(5.0 \% \mathrm{MKF})$ & $3.49 \pm 0.34^{\mathrm{b}}$ & $44.08 \pm 2.81^{\mathrm{b}}$ & $1.28 \pm 0.05^{\mathrm{b}}$ & $2.70 \pm 0.16^{\mathrm{b}}$ \\
$\mathrm{D}(7.5 \% \mathrm{MKF})$ & $3.31 \pm 0.01^{\mathrm{b}}$ & $49.31 \pm 2.28^{\mathrm{ab}}$ & $1.52 \pm 0.10^{\mathrm{a}}$ & $2.96 \pm 0.22^{\mathrm{a}}$ \\
\hline
\end{tabular}

Values are presented as mean \pm standard deviation (mean $\pm 1, \mathrm{n}=4$ ).

Values with different superscript letter in the same column are significant different at $\mathrm{p}<0.05$. 
Formulation D showed the highest amounts of cooking loss compared with other formulations where the MKF incorporation were lower than $7.5 \%$. The trend of the results showed the increase in the cooking loss value as the amount of MKF used was increased. The mixing of non-gluten powder into the semolina flour may disturbs the semolina protein matrix which was developed from the combination of disulphide, hydrogen and hydrophobic bond link (Sissons, 2008).

As a result, the protein matrix breaks down gradually during cooking process followed by releasing exudates during gelatinisation of starch granules and increase the cohesiveness and stickiness of the surface of cooked pasta. This disruption therefore increases the cooking loss. This situation was also reported by RayasDuarte et al., 1996 and Foschia et al., 2015.

Cleary and Brennan (2006) were also explained about this effect where a partial or complete substitution of durum wheat semolina with other non-gluten flour reduced the quality of pasta such as increasing the cooking loss.

Water absorption is known to be positively correlated with swelling index. In this study, the swelling index was only increased at the 7.5\% MKF incorporation level. On the other hand, water absorption decreased as the MKF was introduced into the product but slightly increased again at $7.5 \%$ which resulted in no significant difference from the control sample.
The swelling index is an indication of the water absorption by the starch and protein for gelatinisation and hydration during the cooking processs. However, from the results obtained, the absorption of water and its correlation on the incorporation of MKF with the swelling index is not fully understood.

\section{Colour Value of Fresh Mango Kernel Pasta}

Table 4 shows the colour profile regarding the lightness $\left(\mathrm{L}^{*}\right)$ of pasta incorporated with mango kernel (Mangifera indica) flour. The formulation A gives the yellow colour as the -carotene components contained in semolina (Kill \& Turnbull, 2001). However, the L*-values of pasta decreased as the MKF levels were increased, indicating that the samples became darker when compared to the control sample.

This is because the ash content of pasta increased (Kill \& Turnbull, 2001) with the addition of MKF which increased the mineral content of the pasta. The result of this study is supported by the findings of Sant'Anna et al. (2014) which show that the pasta became darker and $\mathrm{L}^{*}$-values decreased as the incorporation of grape marc powder increased. In addition, Aslam et al. (2014) explained that MKF consists of peroxidase and polyphenols which cause the enzymatic browning, so the lightness of biscuit incorporated with mango kernel powder decreased.

Table 4: Colour value of pasta incorporated with MKF

\begin{tabular}{cccc}
\hline \multirow{2}{*}{ Samples } & \multicolumn{3}{c}{ Colour Value } \\
\cline { 2 - 4 } & $\mathbf{L}^{*}$ & $\mathbf{a}^{*}$ & $\mathbf{b}^{*}$ \\
\hline $\mathrm{A}(0 \% \mathrm{MKF})$ & $74.40 \pm 0.38^{\mathrm{a}}$ & $-2.33 \pm 0.13^{\mathrm{c}}$ & $22.13 \pm 0.19^{\mathrm{a}}$ \\
$\mathrm{B}(2.5 \% \mathrm{MKF})$ & $70.26 \pm 0.17^{\mathrm{b}}$ & $1.81 \pm 0.10^{\mathrm{b}}$ & $20.01 \pm 0.46^{\mathrm{b}}$ \\
$\mathrm{C}(5.0 \% \mathrm{MKF})$ & $69.15 \pm 0.48^{\mathrm{c}}$ & $2.89 \pm 0.20^{\mathrm{a}}$ & $19.51 \pm 0.39^{\mathrm{b}}$ \\
$\mathrm{D}(7.5 \% \mathrm{MKF})$ & $69.04 \pm 0.43^{\mathrm{bc}}$ & $2.82 \pm 0.03^{\mathrm{a}}$ & $18.04 \pm 0.26^{\mathrm{c}}$ \\
\hline
\end{tabular}

Values are presented as mean \pm standard deviation (mean $\pm 1, n=4)$.

Values with different superscript letter in the same column are significant different at $\mathrm{p}<0.05$. 
The trend of $\mathrm{a}^{*}$ values increased, where negative value showed greenness of the product, while $b^{*}$ values (yellowness) have a decreasing trend. This is because the pasta samples were getting darker as the increased of MKF which is one of the fibre and also increasing in fibre content.

\section{Texture Value of Fresh Mango Kernel Pasta}

Table 5 shows the effect of MKF incorporation on the firmness and tensile strength of pasta. The incorporation of MKF of up to 5\% did not reduce the firmness of pasta significantly $(\mathrm{p}>$ $0.05)$. Increasing the MKF content by more than $5 \%$ reduced the firmness of pasta as shown in the Formulation D. The decreasing trend of firmness may be due to higher amount of water absorption and swelling index which cause the starch to swell hence ruptures the protein-starch network accordingly and reducing the amount of pre-gelatinised starch (Padalino et al., 2013).

Tensile strength refers to breaking energy or elasticity of cooked pasta. There was a decreasing trend in the tensile strength value of pasta with the increasing of MKF incorporation. Substituting semolina flour with MKF at 7.5\% had significantly reduced the tensile strength of pasta. The reason was similar as in the case of firmness where due to the physical disruption of protein-starch matrix as a result of higher swelling index which promotes the absorption of water. Consequently, the gluten network is diluted and rupturing the starch granule.

This phenomenon was similarly described by Foo et al. (2011) when green banana peel flour was incorporated into yellow alkaline noodles, a decrease in the tensile strength values was observed as a result of gluten dilution effect.

Table 5: Firmness and tensile strength value of MKF pasta

\begin{tabular}{lll}
\hline Samples & Firmness & Tensile Strength \\
\hline A $(0 \%$ MKF $)$ & $4.91 \pm 0.28^{\mathrm{a}}$ & $64.23 \pm 5.02^{\mathrm{a}}$ \\
B $(2.5 \% \mathrm{MKF})$ & $5.21 \pm 0.45^{\mathrm{a}}$ & $64.59 \pm 1.35^{\mathrm{a}}$ \\
C $(5.0 \% \mathrm{MKF})$ & $5.18 \pm 0.23^{\mathrm{a}}$ & $52.41 \pm 2.62^{\mathrm{b}}$ \\
D $(7.5 \% \mathrm{MKF})$ & $3.96 \pm 0.31^{\mathrm{b}}$ & $37.77 \pm 6.47^{\mathrm{c}}$ \\
\hline
\end{tabular}

Values are presented as mean \pm standard deviation (mean $\pm 1, n=4$ ).

Values with different superscript letter in the same column are significant different at $\mathrm{p}<0.05$.

\section{Scanning Electron Microscope (SEM) of Cooked Pasta}

SEM technique was used to investigate the structural integrity of cooked pasta with different percentage of incorporation of MKF in pasta. Figure 1 shows the surface of cooked pasta under $250 \mathrm{x}$ magnification, whereas the crosssection surface of cooked pasta under $3000 \mathrm{x}$ magnification is shown as Figure 2.

In Figure 1, the pasta without MKF shows a smoother surface compared to other formulations with MKF. Higher incorporation of MKF showed the surface was rougher as seen in Figure 1 where Formulation D was rougher than Formulation $\mathrm{C}$ and $\mathrm{B}$. This may be due to the disruption of continuous protein network by non-gluten flour to cause the surface pasta would no longer smooth. Sudha and Leelavathi (2012) mentioned that the smooth protein film coated the entire surface of cooked control pasta in their study.

Variation in the network of starch granules and protein matrix were observed at higher magnification of $3000 \mathrm{x}$ in the micrographs of cooked pasta with different formulations as shown in Figure 2. Based on diagram A (Figure 2 ), there is gelatinised starch granules were entrapped within protein matrix. These findings were supported by Jyotsna et al. (2004) who stated that the formation of thin film of protein network shows that pasta is of good quality and the enveloping of entire gelatinised starch 
granules is important in determining the cooking quality of pasta products.

However, the diagrams of pasta incorporated with MKF showed the big round particles within the protein-starch network and the amount of big round particles increased with the increase in MKF. In diagram B (Figure 2), the big round particles which were assumed to be MKF particles seem matched with the protein-starch matrix due to the small amount of percentage MKF was added into pasta.

Nevertheless, the Figure 2 (C) and Figure 2 (D) showed the increasing of mango kernel granules inclusion increased the disruption to the protein-starch-fiber network, giving rise to a highly porous structure.
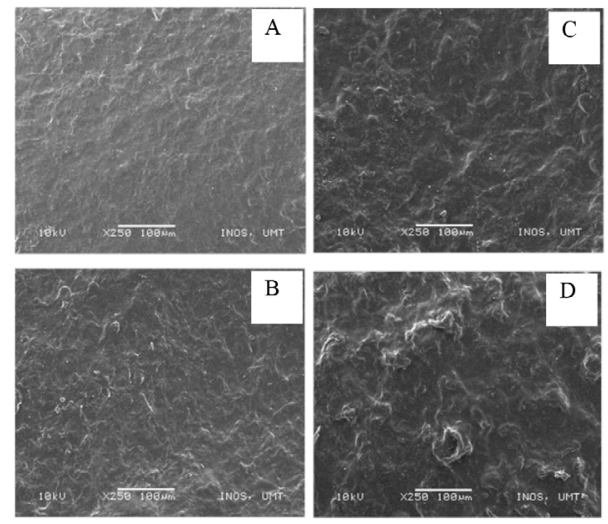

Figure 1: Scanning electron micrographs of exterior surface of cooked pasta (A: $0 \%$ MKF, B: $2.5 \%$ MKF, C: $5.0 \% \mathrm{MKF}, \mathrm{D}: 7.5 \% \mathrm{MKF}$ ) with magnification of $250 \mathrm{x}$
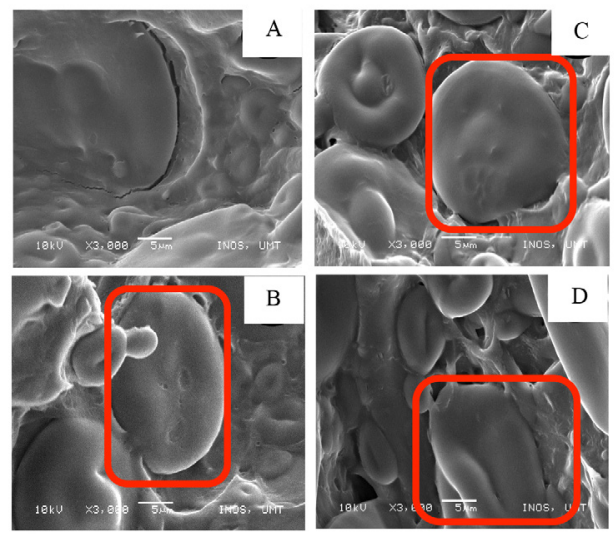

Figure 2: Scanning electron micrographs of cross section of cooked pasta (A: $0 \% \mathrm{MKF}, \mathrm{B}: 2.5 \% \mathrm{MKF}, \mathrm{C}$ :

$5.0 \%$ MKF, D: $7.5 \% \mathrm{MKF}$ ) with magnification of $3000 \mathrm{x}$

Antioxidant Analysis of Fresh Mango Kernel Pasta

Antioxidant properties of different percentages of incorporation MKF in pasta samples were studied and shown in Table 6. Total phenolic content (TPC) is to determine the phenolic profiles including free and bound phenolic acids in the pasta, while DPPH scavenging activity and FRAP are to determine the antioxidant capacity of pasta incorporated with MKF.

TPC and FRAP amounts were significantly increased at the lowest MKF concentrations showing that MKF was very high in phenolic content. Subsequent additions of MKF had 
increased the phenolic content and FRAP in pasta up to $177.01 \pm 1.49 \mathrm{mg} \mathrm{GAE} / 100 \mathrm{~g}$ DW and $4.06 \pm 0.04 \mathrm{mM} / \mathrm{g}$ DW respectively. At least $5 \%$ of MKF was needed to significantly increase the DPPH activity in pasta. There was an increase in TPC, DPPH free radical scavenging activity and FRAP as the MKF content in the pasta samples was increased.
Thus, the study proves that the incorporation of MKF can increase the antioxidant properties of pasta. These results are supported by the findings of Kaur and Brar (2017) showing that the antioxidant activity of biscuits increased with the addition of mango seed kernel flour.

Table 6: The antioxidant properties of pasta incorporated with MKF

\begin{tabular}{cccc}
\hline & \multicolumn{3}{c}{ Antioxidant Properties } \\
\cline { 2 - 4 } Samples & $\begin{array}{c}\text { Total Phenolic Content } \\
\text { Gallic Acid Equivalent (mg } \\
\text { GAE/100 g dry matter) }\end{array}$ & $\begin{array}{c}\text { Antioxidant } \\
\text { Scavenging Activity } \\
\text { (DPPH) (\%) }\end{array}$ & $\begin{array}{c}\text { Ferric Reducing Ability } \\
\text { Iron (II) Sulphate } \\
\text { Equivalent (mM/g dry } \\
\text { matter) }\end{array}$ \\
\hline A (0\% MKF) & $29.14 \pm 1.27^{\mathrm{d}}$ & $78.02 \pm 4.97^{\mathrm{c}}$ & $2.31 \pm 0.03^{\mathrm{d}}$ \\
$\mathrm{B}(2.5 \% \mathrm{MKF})$ & $117.79 \pm 2.23^{\mathrm{c}}$ & $81.87 \pm 2.02^{\mathrm{bc}}$ & $3.54 \pm 0.08^{\mathrm{c}}$ \\
$\mathrm{C}(5.0 \% \mathrm{MKF})$ & $165.64 \pm 4.36^{\mathrm{b}}$ & $85.35 \pm 2.23^{\mathrm{ab}}$ & $3.96 \pm 0.08^{\mathrm{b}}$ \\
$\mathrm{D}(7.5 \% \mathrm{MKF})$ & $177.01 \pm 1.49^{\mathrm{a}}$ & $87.79 \pm 1.61^{\mathrm{a}}$ & $4.06 \pm 0.04^{\mathrm{a}}$ \\
\hline
\end{tabular}

Values are presented as mean \pm standard deviation (mean $\pm 1, n=4$ ).

Values with different superscript letter in the same column are significant different at $\mathrm{p}<0.05$.

Sensory Evaluation of Fresh Mango Kernel Pasta

Table 7 shows the result of sensory acceptability of pasta incorporated with MKF. At least 5\% of MKF was required to show a significant reduction in the acceptability of pasta's colour. As the MKF levels in the pasta increased, the original yellow colour of pasta became darker. A consumer may not be familiar with the darker colour of the pasta and so decrease the colour score of the pasta with higher amounts of MKF.

In terms of odour, flavour and overall acceptability, MKF basically did not influence the acceptability of pasta where all samples showed no significant difference $(p>0.05)$ when compared with each other. Different observations were seen in the acceptability of pasta's texture where, a 5\% MKF incorporation had reduced the acceptability of pasta significantly $(\mathrm{P}<0.05)$. However, an increase of $7.5 \%$ or more did not reduce the acceptability of the pasta which showed comparable scores between Formulation A and Formulation B.

Comparing the texture result in Table 5, $7.5 \%$ of MKF had reduced the firmness and tensile strength of pasta thus supposed showing a lower score for sensory evaluation. Since all panellists were untrained, it is likely that the panellists were unable to differentiate the acceptability of pasta in terms of texture thus, showing no trend in the acceptability of pasta's texture as the MKF was increased.

Therefore, from the result of sensory, at least $2.5 \%$ of MKF was considered as the most acceptable pasta where at least it showed a comparable acceptability with the control sample in all attributes tested. Nevertheless, excluding the colour attribute as colour is just the appearance of pasta, pasta with up to $7.5 \%$ MKF could also be considered as an acceptable product for all other attributes. 
Table 7: Sensory evaluation of pasta incorporated with MKF

\begin{tabular}{cccccc}
\hline Samples & Colour & Odour & Texture & Flavour & Overall Acceptability \\
\hline A $(0 \%$ MKF $)$ & $5.83 \pm 1.12^{\mathrm{a}}$ & $5.20 \pm 1.10^{\mathrm{a}}$ & $5.57 \pm 1.20^{\mathrm{a}}$ & $4.93 \pm 1.48^{\mathrm{a}}$ & $5.37 \pm 1.25^{\mathrm{a}}$ \\
B (2.5\% MKF) & $5.47 \pm 0.90^{\mathrm{ab}}$ & $5.03 \pm 1.16^{\mathrm{a}}$ & $4.97 \pm 1.07^{\mathrm{ab}}$ & $5.10 \pm 1.06^{\mathrm{a}}$ & $5.17 \pm 0.91^{\mathrm{a}}$ \\
C $(5.0 \% \mathrm{MKF})$ & $5.07 \pm 1.11^{\mathrm{bc}}$ & $5.00 \pm 1.23^{\mathrm{a}}$ & $4.67 \pm 1.37^{\mathrm{b}}$ & $4.67 \pm 1.09^{\mathrm{a}}$ & $4.87 \pm 1.07^{\mathrm{a}}$ \\
$\mathrm{D}(7.5 \% \mathrm{MKF})$ & $4.73 \pm 1.05^{\mathrm{c}}$ & $4.70 \pm 1.18^{\mathrm{a}}$ & $5.03 \pm 1.35^{\mathrm{ab}}$ & $4.40 \pm 1.43^{\mathrm{a}}$ & $4.80 \pm 0.96^{\mathrm{a}}$ \\
\hline
\end{tabular}

Values are presented as mean \pm standard deviation (mean $\pm 1, n=4$ ).

Values with different superscript letter in the same column are significant different at $\mathrm{p}<0.05$.

\section{Conclusion}

The substitution of MKF generally not affected the nutritional composition of pasta except for the highest MKF where it significantly increased the crude fat content. While, MKF had reduced the cooking time at $5 \%$ incorporation, increased the water absorption at the lowest level of incorporation, increased the swelling index at $7.5 \%$ incorporation and increased the cooking loss at $5 \%$ incorporation.

MKF had also influenced the colour of pasta where pasta was significantly reduced in lightness at the lowest level of incorporation. In terms of texture, the firmness of pasta was only reduced at the highest percentage of MKF while tensile strength was reduced at 5\% incorporation of MKF.

Replacing some of the semolina flour with MKF was observed to produce pasta with a rougher surface. The high levels of MKF had increased the antioxidant properties of the pasta even at the lowest level of MKF substitution.

An at least 5\% MKF to semolina substitution was required to increase the DPPH activity of pasta. MKF influenced the acceptability of pasta both in terms of colour and texture. Other attributes like odour, flavor and overall acceptability were not affected by the incorporation of MKF.

In conclusion, a pasta with a $2.5 \% \mathrm{MKF}$ incorporation was chosen as the most preferred pasta. Especially based on that variant's ability not to affect the acceptability of pasta and other physicochemical properties, it had all the benefits of increased antioxidant properties without any of the drawbacks of texture or colour associated with pasta that had been incorporated with MKF.
Therefore, MKF has high potential to be used as an ingredient to increase the antioxidant properties of food products especially pasta.

\section{Acknowledgements}

This work was a final year project under the supervision of Dr. Nizaha Juhaida Mohamad. Many thanks to the Department of Food Science under the Faculty of Fisheries and Food Science, Universiti Malaysia Terengganu for giving me this opportunity and providing decent facilities in which to conduct the experiments and other necessities of this project and to put into practice the knowledge that I acquired in my university. I would also like to thank the laboratory staff for their expertise and technical support.

\section{References}

Abdalla, D. M., Ahmed, E. M., Eman, H. E. A., \& Reham, M. E. 1H. (2007). Egyptian mango by-product 1 . Compositional quality of mango seed kernel. Food Chemistry, 103(4): 1134-1140.

AACC. (1995). Approved Methods of the American Association of Cereal Chemists. 9th Ed. Methods 44.15 A, 46-30, 08-01, 16-50 and 14-22, American Association of Cereal Chemists. St. Paul, MN.

AACC. (2003). Approved methods of the AACC. American Association of Cereal Chemists St. Paul, MN.

AACC. (2005). Approved Methods of the AACC. 11th Ed., American Association of Cereal Chemists, St. Paul, MN. 
AOAC. (1990). Official Methods of Analysis of the Association of Official Analytical Chemists. 15th ed. Association of Official Analytical Chemists, Arlington, VA, USA.

Aravind, N., Sissons, M., Egan, N., \& Fellows, C. (2012). Effect of insoluble dietary fibre addition on technological, sensory, and structural properties of durum wheat spaghetti. Food Chemistry, 130(2), 299309.

Aslam, H. K. W., Raheem, M. I. U., Ramzan, R., Shakeel, A., Shoaib, M.. \& Sakandar, H. A. (2014). Utilization of mango waste material (peel, kernel) to enhance dietary fiber content and antioxidant properties of biscuit. Journal of Global Innovations in Agricultural and Social Sciences, 2, 76-81.

Ashoush, I.S., \& Gadallah, M.G.E. (2011). Utilisation of mango peels and seed kernels powders as sources of phytochemicals in biscuit. World Journal of Dairy Food Science. 6 (1): 35-42.

Beerh, O. P., Raghuramaiah, B., Krishnamurthy, G. V., \& Giridhar, N. (1976). Utilization of mango waste: recovery of juice from waste pulp and peel. Journal of Food Science and Technology (Mysore), 13(23), 138-141.

Benzie, F. F., \& Strain, J. J. (1999). Ferric Reducing/ Antioxidant Power Assay: Direct measure of total antioxidant activity of biological fluids and modified version for simultaneous measurement of total antioxidant power and ascorbic acid concentration. Methods Enzymol, 9, 15-23.

Beta, T., Nam, S., Dexter, J. E., \& Sapirstein, H. D. (2005). Phenolic content and antioxidant activity of pearled wheat and roller-milled fractions. Cereal Chemistry, 82(4), 390393.

Central Food Technological Research Institute (CFTRI). (1985). Mango pulp concentration, p. 25-39. Mysore, India.

Cleary, L., \& Brennan, C. (2006). The influence of $\alpha(1 \rightarrow 3)(1 \rightarrow 4)-\beta$-D-glucan rich fraction from barley on the physico-chemical properties and in vitro reducing sugars release of durum wheat pasta. International Journal of Food Science and Technology, 41: 910-918.

Croce, J. D. (1997). Pasta. London: Dorling Kindersley Limited. Pp. 49-52.

FAOSTAD, F., (2015). A. organization of the United Nations. FAO. Retrieved from http://faostat.fao.org/site/339/default.aspx

Foo, W. T., Yew, H. S., Liong, M. T., \& Azhar, M. E. (2011). Influence of formulations on textural, mechanical and structural breakdown properties of cooked yellow alkaline noodles. International Food Research Journal, 18(4).

Foschia, M., Peressini, D., Sensidoni, A., Brennan, M. A., \& Brennan, C. S. (2015). How combinations of dietary fibres can affect physicochemical characteristics of pasta. LWT-Food Science and Technology, 61(1), 41-46.

Gan, C. Y., Ong, W. H., Wong, L. M., \& Easa, A. M. (2009). Effects of ribose, microbial transglutaminase and soy protein isolate on physical properties and in vitro starch digestibility of yellow noodles. Lebensmittel-Wissenschaft. Und -Technologie, 42, 174-179.

Gull, A., Kamlesh P., \& Pradyuman K. (2015). Effect of millet flours and carrot pomace on cooking qualities, color and texture of developed pasta. LWT-Food Science and Technology, 63(1), 470-474.

Hemavathy, J., Prabhakar, J. V., \& Sen, D. P. (1988). Drying and storage behaviour of mango (Mangifera indica) and Composition of kernel fat.Asian Food Journal, 4, 59-63.

Ibarra, I., Ramos, P., Hernández, C., \& Jacobo, D. (2015). Effects of post harvest ripening on the nutraceutical and physicochemical properties of mango (Mangifera indica L. cv Keitt). Postharvest Biology and Technology, 103(0), 45-54.

Ifesan, B.O.T. (2017). Chemical Properties of Mango Kernel and Seed and Production of 
Biscuit from Wheat-mango Kernel Flour Blends. International Journal of Food and Nutrition Research, 1,5.

Kaur, G., Sharma, S., Nagi, H. P. S., \& Dar, B. N. (2012). Functional properties of pasta enriched with variable cereal brans. Journal of Food Science and Technology, 49(4), 467-474.

Kaur, A., \& Brar, J. K. (2017). Use of mango seed kernels for the development of antioxidant rich health foods. Food Science Research Journal, 8(2), 368-374.

Kill, R. C., \& Turnbull, K. (2001). Pasta and semolina technology. Malden: Blackwell Science.

Loelillet, D. (1994). The European mango market: A promising tropical fruit. Fruit, 49,332-334.

Maisuthisakul, P., \& Gordon, M. H. (2009). Antioxidant and tyrosinase inhibitory activity of mango seed kernel by product. Food Chemistry, 117, 332-341.

Masibo, M., \& He, Q. (2008). Major mango polyphenols and their potential significance to human health. Comprehensive Reviews in Food Science and Food Safety, 7(4), 309319.

Menon, L., Majumdar, S. D., \& Ravi, U. (2014). Mango (Mangifera indica L.) kernel flour as a potential ingredient in the development of composite flour bread. Indian Journal of Natural Products and Resources, 5(1). pp. 75-82.

Okpala, L. C., \& Gibson-Umeh, G. I. (2013). Physicochemical properties of mango seed flour. Nigerian Food Journal, 31(1), 23-27.

Omobuwajo, T. O. (2003). Compositional characteristics and sensory quality of biscuits, prawn crackers and fried chips produced from beadfruit. Innovative Food Science \& Emerging Technologies, 4(2), 219-225.

Padalino, L., Mastromatteo, M., Lecce, L., Cozzolino, F., \& Del Nobile, M. A. (2013).
Manufacture and characterization of glutenfree spaghetti enriched with vegetable flour. Journal of Cereal Science, 57, 333-34.

Petitot, M., Boyer, L., Minier, C., \& Micard, V. (2010). Fortification of pasta with split pea and faba bean flours: Pasta processing and quality evaluation. Food Research International, 43(2), 634-641.

Prabhasankar, P., Ganesan, P., \& Bhaskar, N. (2009a). Influence of Indian brown seaweed (Sargassum marginatum) as an ingredient on quality, biofunctional, and microstructure characteristics of pasta. Food Science and Technology International, 15(5), 471-479.

Prabhasankar, P., Ganesan, P., Bhaskar, N., Hirose, A., Stephen, N., Gowda, L.R., Hosokawa, M., \& Miyashita, K., 2009 b. Edible Japanese seaweed, wakame (Undaria pinnatifida) as an ingredient in pasta: Chemical, functional and structural evaluation. Food Chemistry, 115(2), 501508.

Puravankara, D., Boghra, V., \& Sharma, R. S. (2000). Effect of antioxidant principles isolated from mango (Mangifera indica L.) seed kernels on oxidative stability of buffalo ghee (butter-fat). Journal of the Science of Food and Agriculture, 80, 522-526.

Ramteke, R. S., \& Eipeson, W. E. (1997). Effect of additives on the stability of mango aroma concentrate during storage. Journal of Food Science and Technology, 34(3), 195-199.

Rayas-Duarte, P., Mock, C. M., \& Satterlee, L. D. (1996). Quality of Spaghetti Containing Buckwheat, Amaranth and Lupin Flours. Cereal Chemistry, 73(3), 381-387.

Sant'Anna, V., Christiano, F. D. P., Marczak, L. D. F., Tessaro, I. C., \& Thys, R. C. S. (2014). The effect of the incorporation of grape marc powder in fettuccini pasta properties. LWT-Food Science and Technology, 58(2), 497-501.

Seleim, M. A., Rashwan, M. R. A., \& Ragab, W. S. M. (1999). Biological value assessment of the meal and protein isolate of mango 
seed kernels. Journal of Agricultural and Science, Mansoura University, 24(9), 4895-4905.

Singleton, V.L., Orthofer, R., \& LamuelaRavento's, R.M. (1999). Analysis of total phenols and other oxidation substrates and antioxidants by means of Folin-Ciocalteu reagent. Methods in Enzymology, 299, 152178.

Sissons, M. (2008). Role of durum wheat composition on the quality of pasta and bread. Food, 2,75-90.

Soong, Y. Y., Barlow, P. J., \& Perera, C. O. (2004). A cocktail of phytonutrients: Identification of polyphenols, phytosterols and tocopherols from mango (Mangifera indica L.) seed kernel. In IFT annual meeting, July 12-16, Las Vegas.

Sudha, M. L., \& Leelavathi, K. (2012). Effect of blends of dehydrated green pea flour and amaranth seed flour on the rheological, microstructure and pasta making quality. Journal of Food Science and Technology, 49(6), 713-720.

Tharanathan, R., Yashoda, H., \& Prabha, T. (2006). Mango (Mangifera indica L.), "The King of Fruits"-An Overview. Food Reviews International, 22(2), 95-123.

Thomas, D., Brotherhood, J., \& Brand, J. (1991). Carbohydrate Feeding before Exercise: Effect of Glycemic Index. International Journal of Sports Medicine, 12(02), 180186.

Yatnatti, S., Vijayalakshmi, D., \& Chandru, R. (2014). Processing and Nutritive Value of Mango Seed Kernel Flour. Current Research in Nutrition and Food Science Journal, 2(3), 170-175. 
